\title{
Study of Potential Utility of New Radiopharmaceuticals Based on Technetium-99m Labeled Derivative of Glucose
}

\author{
R. Zeltchan ${ }^{1,2, a)}$, A. Medvedeva ${ }^{1,2}$, I. Sinilkin ${ }^{1,2}$, V. Chernov ${ }^{1,2}$, E. Stasyuk ${ }^{2}$, \\ A. $\operatorname{Rogov}^{2}$, E. Il'ina ${ }^{2}$, L. Larionova ${ }^{2}$, and V. Skuridin ${ }^{2}$ \\ ${ }^{1}$ Tomsk Cancer Research Institute, Tomsk, 634050 Russia \\ ${ }^{2}$ Tomsk Polytechnic University, Tomsk, 634050 Russia

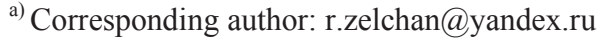

\begin{abstract}
Purpose: to study the potential utility of 1-thio-D-glucose labeled with ${ }^{99 \mathrm{~m}} \mathrm{Tc}$ for cancer imaging in laboratory animals. Materials and method: the study was carried out in cell cultures of normal CHO (Chinese hamster ovary cells CHO) and malignant tissues MCF-7 (human breast adenocarcinoma MCF-7). To evaluate the uptake of ${ }^{99 \mathrm{~m}}$ Tc-1-thio-Dglucose in normal and tumor tissue cells, $25 \mathrm{MBq}$ of 1-thio-D-glucose labeled with ${ }^{99 \mathrm{~m}} \mathrm{Tc}$ was added to the vials with 3 million cells and incubated for $30 \mathrm{~min}$ at room temperature. After centrifugation of the vials with cells, the supernatant was removed. The radioactivity in vials with normal and tumor cells was then measured. In addition, the study included 40 mice of C57B1/6j lines with tumor lesion of the right femur. For neoplastic lesions, Lewis lung carcinoma model was used. Following anesthesia, mice were injected intravenously with $25 \mathrm{MBq}$ of ${ }^{99 \mathrm{~m}} \mathrm{Tc}-1$-thio-D-glucose. Planar scintigraphy was performed 15 minutes later in a matrix of $512 \times 512$ pixels for 5 min. Results: when measuring the radioactivity of normal and malignant cells after incubation with ${ }^{99 \mathrm{~m}} \mathrm{Tc}-1$-thio-D-glucose, it was found that the radioactivity of malignant cells was higher than that of normal cells. The mean values of radioactivity levels in normal and malignant cells were $0.3 \pm 0.15 \mathrm{MBq}$ and $1.07 \pm 0.6 \mathrm{MBq}$, respectively. All examined animals had increased accumulation of ${ }^{99 \mathrm{~m}} \mathrm{Tc}-1$-thio-D-glucose at the tumor site. The accumulation of ${ }^{99 \mathrm{~m}} \mathrm{Tc}-1$-thio-D-glucose in the tumor was on average twice as high as compared to the symmetric region. Conclusion: The present study demonstrated that ${ }^{99 \mathrm{~m}} \mathrm{Tc}-1$ thio-D-glucose is a prospective radiopharmaceutical for cancer visualization. In addition, high accumulation of ${ }^{99 \mathrm{~m}} \mathrm{Tc}-1$ thio-D-glucose in the culture of cancer cells and in tumor tissue of animals demonstrates tumor tropism of the radiopharmaceutical.
\end{abstract}

\section{INTRODUCTION}

Nuclear medicine techniques have become an indispensable tool for the diagnosis, treatment planning and management of cancer patients [1,2]. Currently, there is a continuous search for new, more specific and efficient diagnostic and therapeutic radiopharmaceuticals. At the same time, the development of nuclear medicine imaging technologies in Russia is still far behind the world level. It is estimated that the demand for radiopharmaceuticals in Russia is satisfied by no more than $1-3 \%$. A variety of positron-emitting nuclides is currently utilized to detect tumors and metastases as well as to monitor treatment response. The most commonly used PET radiopharmaceutical is a derivative of glucose, namely 2-(18F) fluoro-2-deoxy-glucose (18F-FDG) [3]. Despite the high diagnostic value of 18F-FDG-PET, the widespread use of this imaging modality in Russia is limited because of its high cost and lack of PET centers. In spite of advances in PET technologies worldwide, a large number of nuclear medicine laboratories in Russia are still equipped with gamma cameras. There are more than 200 SPECT (single photon emission computed tomography) centers in Russia. The most frequently used radionuclide for SPECT is technetium$99 \mathrm{~m}$, therefore, it seems relevant to develop innovative radiopharmaceuticals for molecular imaging based on technetium-99m-labeled glucose derivatives [4-6]. The main advantage of radiotracers based on technetium-99mlabeled glucose derivatives is the ability to image different tumor types using a gamma camera, thus significantly reducing the cost of the diagnostic procedure. 


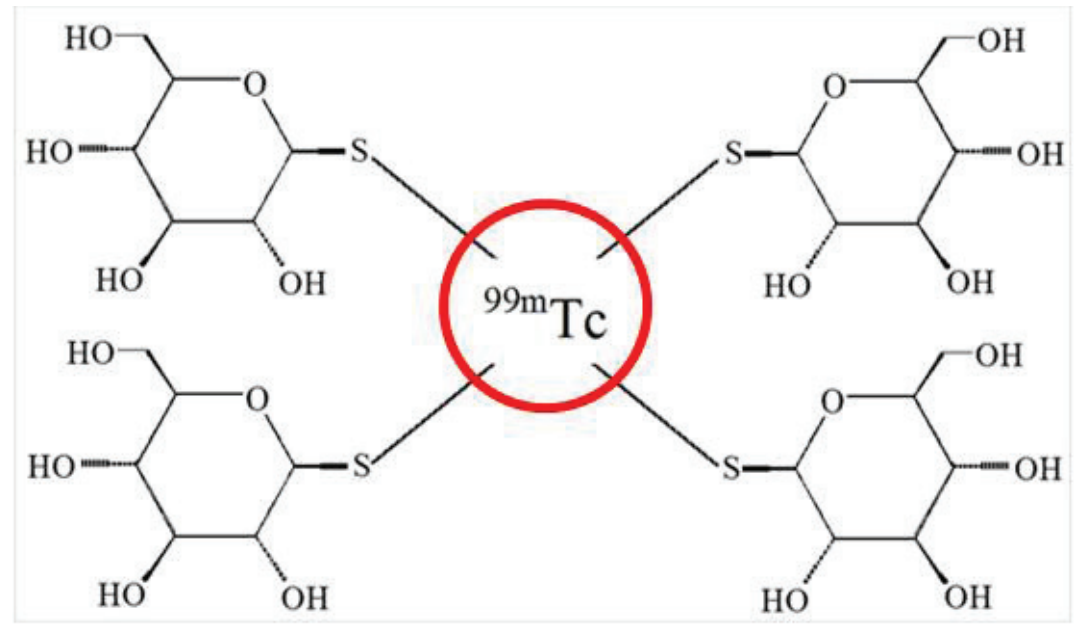

FIGURE 1. Chemical structure of ${ }^{99 \mathrm{~m}} \mathrm{Tc}-1$-thio-D-glucose

A new tumor seeking agent, ${ }^{99 \mathrm{~m}}$ Tc-labeled 1-thio-D-glucose, is one of these radiotracers (Fig. 1). It was developed at the Polytechnic University and Cancer Research Institute (Tomsk, Russia). It is currently under preclinical safety testing at the Tomsk Cancer Research Institute. Thus, the purpose of the present study was to evaluate the potential utility of ${ }^{99 \mathrm{~m}} \mathrm{Tc}-1$-thio-D-glucose for tumor tissue imaging in animals.

\section{MATERIALS AND METHODS}

The radiopharmaceutical ${ }^{99 \mathrm{~m}} \mathrm{Tc}$-1-thio-D-glucose) was prepared from the reagent (lyophilizate) by adding $4 \mathrm{ml}$ of sodium pertechnetate $\left({ }^{99 \mathrm{~m}} \mathrm{Tc}\right)$. The composition of reagent (lyophilizate) was a solution of 1-thio-D-glucose in the presence of tin (II) chloride dihydrate $\left(\mathrm{SnCl}_{2} \cdot 2 \mathrm{H}_{2} \mathrm{O}\right)$. After adding the reagent into a sterile vial, ${ }^{99 \mathrm{~m}} \mathrm{Tc}$ sodium pertechnetate solution was incubated for $30 \mathrm{~min}$ at room temperature. The finished solution was a clear, colorless liquid. Description of the radiopharmaceutical: clear liquid, $\mathrm{pH}$ from 4.0 to $8.0(6 \pm 2)$; radiochemical impurity was not more than $8 \%$. Radionuclide impurities: ${ }^{99} \mathrm{Mo}$ - no more than $2 \times 10^{-3} \%$, others- no more than $1 \times 10^{-4} \%$. The concentration of sodium chloride ranged from 8.0 to $10.0 \mathrm{mg} / \mathrm{ml}$. The content of the derivative of 1-thio-D-glucose was not more than $0.625 \mathrm{mg} / \mathrm{ml}$. The content of tin dichloride dehydrate was $0.044-0.052 \mathrm{mg} / \mathrm{ml}$. Gamma spectrum ${ }^{99 \mathrm{~m}}$ Tc 1-thio-D-glucose had a characteristic line with the energy of $0.140 \mathrm{MeV}$.

The potential utility of ${ }^{99 \mathrm{~m}} \mathrm{Tc}$-1-thio-D-glucose for tumor imaging was studied in vitro and in vivo models. In vitro studies, the cell cultures from normal (Chinese hamster ovary (CHO) cells) and cancer tissues (MCF 7-human breast adenocarcinoma cell line) were used. To evaluate the uptake of ${ }^{99 \mathrm{~m}} \mathrm{Tc}-1$-thio-D-glucose in normal and tumor tissue cells, $25 \mathrm{MBq}$ in $200 \mu \mathrm{L}$ of technetium-99m-labeled glucose derivative was added to vials with 3000000 cells $/ \mathrm{ml}, 5$ vials for each cell culture. The vials with cells were then incubated for 30 minutes at room temperature with periodic gentle shaking to avoid cell adhesion. After completion of incubation, the vials were centrifuged at $300 \mathrm{rpm}$ for $5 \mathrm{~min}$. After sedimentation, the supernatant was removed carefully and the radioactivity measurement of the sediment and supernatant was made. Thereafter, the cells were washed three times by adding $1 \mathrm{ml}$ of buffer to each vial and centrifugation vials. PBS $+1 \%$ BCA were used as a buffer.

The radioactivity in the sediment and supernatant was measured after each washing. After the final cell washing, cell-labeling efficiency, a percentage of ${ }^{99 \mathrm{~m}}$ Tc-labeled 1-thio-D-glucose accumulation in normal and cancer tissue cells was measured. In addition, planar scintigraphic imaging of the culture plates with vials was performed.

In vivo studies, the potential utility of ${ }^{99 \mathrm{~m}} \mathrm{Tc}$-labeled 1 -thio-D-glucose for tumor visualization was studied using the intramuscularly implanted solid Lewis lung carcinoma model in C57BL/6J mice (Bank of Cell Lines, NN Blokhin Russian Cancer Research Center, Moscow). A total of 40 male and female mice, weighing $30 \pm 5 \mathrm{~g}$ and 12 weeks of age, were used. The tumor size was $2 \pm 0.2 \mathrm{~cm}^{3}$. The acquisition, care and housing of laboratory animals were in compliance with federal and local laws and regulations, as well as with ethical and legal principles of the European Convention for the Protection of Vertebrate Animals (Strasbourg, 1986). Mice were anesthetized by 
inhalation of ethyl ether. To study the ${ }^{99 \mathrm{~m}} \mathrm{Tc}$-labeled 1-thio-D-glucose accumulation in the body of C57BL/6J mice bearing Lewis lung carcinoma, the radiotracer was injected intravenously in diagnostic dose after anesthesia. Whole-body gamma scintigraphy using SiemensE.Cam 180 gamma camera was performed 10-15 min after intravenous injection of the radiotracer. We used the high-resolution, low-energy collimators for140keV energy. The mice were placed with their ventral surface to the gamma camera detector so that the imaging field of view could encompass the whole body of the animal. Each image was acquired for $5 \mathrm{~min}$. About 500,000 counts were recorded in each image with matrix size of $256 \times 256$ pixels. Radioactivity in regions of interest drawn in various organs of the mice and in tumor tissue was measured. Statistical analysis was performed using E.soft Software Version 5.5 (Siemens).

\section{RESULTS}

The radioactivity in normal and tumor tissue cells after the final washing was measured using a gamma counter. The mean radioactivity levels in normal and tumor tissue cells after the final washing were $0.3 \pm 0.15 \mathrm{MBq}$ and $1.07 \pm 0.6 \mathrm{MBq}$, respectively. Thus, the ${ }^{99 \mathrm{~m}} \mathrm{Tc}$-labeled 1-thio-D-glucos uptake in cancer cells (MCF 7) was 3.5 times higher than that in normal tissue cells $(\mathrm{CHO})$. Planar scintigraphic images of plates with culture vials showed more intense radiotracer accumulation in cancer tissue cells (Fig. 2).

Planar scintigraphy was performed on tumor-bearing mice 10-15 min after intravenous injection of $25 \mathrm{MBq}$ of 99mTc-labeled 1-thio-D-glucos. Tumor was visualized in all mice. Most scintigraphic images demonstrated the tumor as a site of extremely high radiotracer uptake with clear contours. The uptake of the radiotracer in the tumor was frequently heterogeneous, with different intensity (Fig. 3).

The changes in 99mTc-labeled 1-thio-D-glucos accumulation in the tumor after intravenous injection are demonstrated in Fig. 4. It should be noted that the maximum concentration of the 99mTc-labeled 1-thio-D-glucos in the tumor is recorded through 2 hours following intravenous administration.

The images obtained showed that the mean radiotracer uptake intensity in the tumor was $2665.8 \pm 431$ counts, while in the symmetrical tissue it was $878.3 \pm 134$ counts. The relative $99 \mathrm{mTc}$-labeled 1-thio-D-glucos uptake in the tumor was higher by $308.9 \pm 94 \%$ than that in the symmetrical tissue. The percentage of the radiotracer tumor uptake from the total injected radiotracer dose was calculated. At 10-15 minutes after intravenous injection, the percentage of $99 \mathrm{mTc}$-labeled 1-thio-D-glucos uptake in the tumor appeared to be $8.14 \%$ of the total injected radiotracer dose. Thus, the use of $99 \mathrm{mTc}$-labeled 1-thio-D-glucos radiotracer for tumor imaging by single photon emission scintigraphy allowed tumor imaging in $100 \%$ of the laboratory mice.

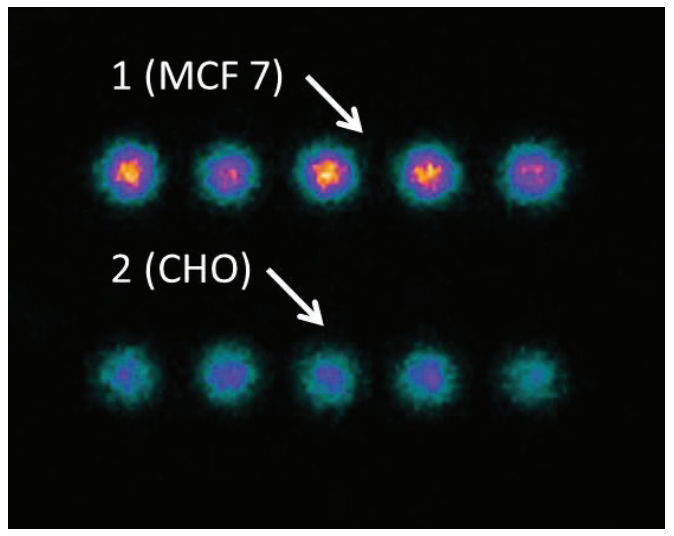

FIGURE 2. Scintigraphic imaging of culture plates containing cancer cells ( 1 ) and normal tissue cells (2) after incubation with ${ }^{99 \mathrm{~m}} \mathrm{Tc}$-labeled 1-thio-D-glucos and 3-time washing

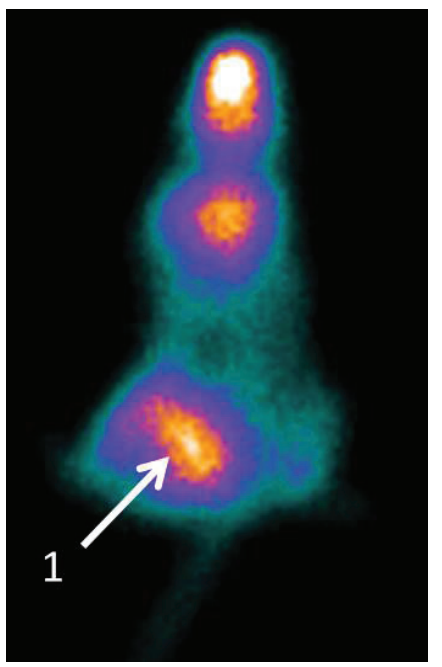

FIGURE 3. Scintigraphic image of tumor-bearing mice at 15 min after intravenous injection of ${ }^{99 \mathrm{~m}} \mathrm{Tc}$-labeled 1-thio-Dglucos. There is an extremely high radiotracer uptake in the tumor of the right femur ( 1 ) 


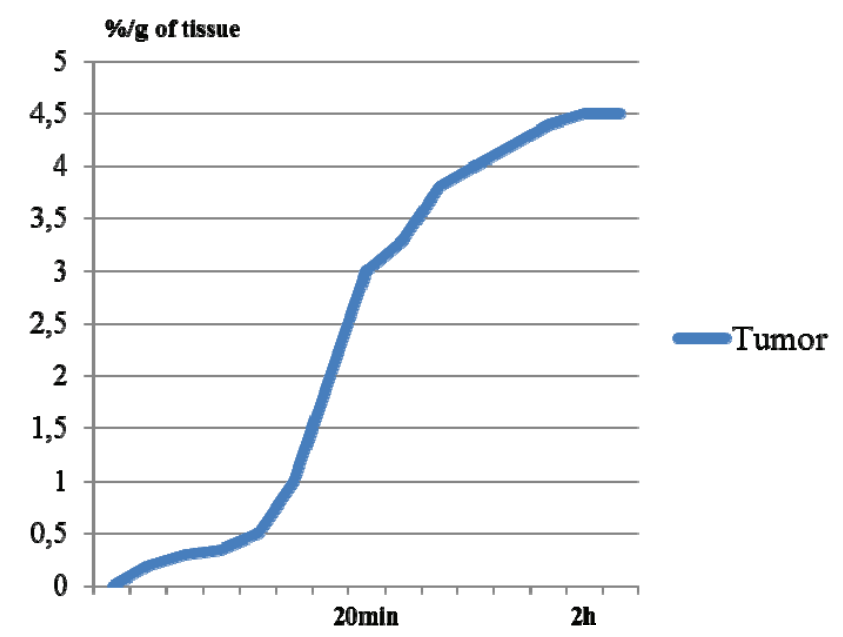

FIGURE 4. The dynamics of ${ }^{99 \mathrm{~m}}$ Tc-labeled 1-thio-D-glucos accumulation in tumors in mice after intravenous administration. The maximum concentration of the ${ }^{99 \mathrm{~m}}$ Tc-labeled 1-thio-D-glucos

in the tumor is recorded through 2 hours following intravenous injection

\section{CONCLUSION}

The results from this study indicate that ${ }^{99 \mathrm{~m}}$ Tc-labeled 1-thio-D-glucos, a new tumor-seeking agent based on technetium-99m-labeled glucose derivative, is a potentially useful tracer for tumor tissue imaging in the laboratory animals. Moreover, in vitro studies demonstrate highly selective accumulation of this radiotracer. The ${ }^{99 \mathrm{~m}}$ Tc-labeled 1-thio-D-glucos uptake in tumor tissue cells was 3 times higher than that in normal tissue cells. However, further pre-clinical studies of ${ }^{99 \mathrm{~m}}$ Tc-labeled 1-thio-D-glucos are necessary to investigate its pharmacokinetics and safety.

\section{ACKNOWLEDGMENTS}

The study reported in this article was conducted according to accepted ethical guidelines involving research in humans and/or animals and was approved by an appropriate institution or national research organization. The study is compliant with the ethical standards as currently outlined in the Declaration of Helsinki. All individual participants discussed in this study, or for whom any identifying information or image has been presented, have freely given their informed written consent for such information and/or image to be included in the published article.

\section{REFERENCES}

1. V. I. Chernov, A. A. Medvedeva, I. G. Sinilkin, R. V. Zeltchan, O. D. Bragina, and V. S. Skuridin, Experience in the development of innovative radiopharmaceuticals in the Tomsk Institute of Oncology, Sib. J. Oncology, 2, 45-47 (2015).

2. R. Van Noorden, Radioisotopes: The medical testing crisis, Nature 504(7479), 202-204 (2013).

3. M. S. Jacobson, J. C. Hung, T. L. Mays, and B. P. Mullan, The planning and design of a new PET radiochemistry facility, Mol. Imaging Biol. 4(2), 119-127 (2002).

4. M. M. Welling and R. Alberto, Performance of a 99mTc-labelled 1-thio-beta-D-glucose 2,3,4,6-tetra-acetate analogue in the detection of infections and tumours in mice: a comparison with [18F]FDG, Nucl. Med. Commun. 31(3), 239-248 (2010).

5. D. Cheng, M. Rusckowski, Y. Wang, Y. Liu, G. Liu, X. Liu, and D. Hnatowich, A brief evaluation of tumor imaging in mice with $99 \mathrm{mTc}$-glucarate including a comparison with $18 \mathrm{~F}-\mathrm{FDG}$, Curr. Radiopharm. 4(1), 5-9 (2011).

6. Y. Chen, Z. W. Huang, L. He, S. L. Zheng, et al., Synthesis and evaluation of a technetium-99m-labeled diethylentriaminepentaacetate-deoxyglucose complex 99mTc-DTPA-DG as a potential imaging modality for tumors, Appl. Radiat. Isot. 64(3), 342-347 (2006). 